\section{Singlet Series in the Spark Spectrum of Aluminium.}

Prof. Paschen's beautiful work on the spark spectra of aluminium has revealed in the case of the singly ionised atom $(\mathrm{Al}+)$, a very complete system of triplets (Annalen der Physik, 7I, 537-56I, I923) analogous to that which appears in the arc spectrum of magnesium. A number of the strongest lines, however, do not find a place in this system, and are obviously members of a system of single lines, like that which exists in the arc spectra of magnesium, calcium, etc.; but he presents no arrangement of these in series.

In the triplet system, the ratios of corresponding terms in $\mathrm{Mg}$ and $\mathrm{Al}+$, if plotted against the values of the terms for Mg, give remarkably smooth curves (different for each series), as is illustrated in the Table below :

(The Numeration follows Bohr's System.)

\begin{tabular}{|c|c|c|c|c|c|c|c|}
\hline & Mg. & $\mathrm{Al}+$. & Ratio. & & Mg. & $\mathrm{Al}+$. & Ratio. \\
\hline $4 s$ & 20475 & 60589 & $2 \cdot 96$ & $3 p_{1}$ & 39760 & $I_{1428 \mathrm{I}}$ & $2 \cdot 88$ \\
\hline $5 s$ & 9799 & $3 \times 770$ & $3 \cdot 24$ & $4 p_{1}$ & 13820 & 46393 & $3 \cdot 35$ \\
\hline $6 s$ & $578 x$ & 19648 & 3.40 & $5 p_{1}$ & 7419 & $26 \mathrm{III}$ & 3.52 \\
\hline $8 s$ & 2709 & $968 \mathrm{r}$ & 3.57 & $7 p_{1}$ & 3185 & Ir767 & 3.70 \\
\hline${ }_{4 S}^{3 S}$ & $\begin{array}{l}6 \times 672 \\
18 \times 69\end{array}$ & $\begin{array}{r}(247107 \cdot 3) \\
(54485 \cdot 6)\end{array}$ & $\begin{array}{l}(2 \cdot 39) \\
(3 \cdot 00)\end{array}$ & $\begin{array}{l}3 P \\
4 P\end{array}$ & $\begin{array}{l}2662 x \\
12325\end{array}$ & $\begin{array}{l}(87262 \cdot 2) \\
(43758 \cdot 9)\end{array}$ & $\begin{array}{l}(3.27) \\
(3.54)\end{array}$ \\
\hline $3 d_{1}$ & 13714 & $563_{14}$ & $4 \cdot \mathrm{II}$ & $4 f_{1}$ & 6995 & 28440 & $4 \cdot 07$ \\
\hline $\begin{array}{l}4 d_{1} \\
5 d_{1}\end{array}$ & $\begin{array}{l}7479 \\
4704\end{array}$ & $\begin{array}{l}30380 \\
1904 x\end{array}$ & 4.06 & $5 f_{\mathrm{I}}$ & 4469 & 18413 & $4 \cdot 13$ \\
\hline $3 u_{1}$ & 704 & & $4 \cdot 05$ & & & & \\
\hline $3 D$ & $\begin{array}{r}15269 \\
8\end{array}$ & $(6 \times 632 \cdot 9)$ & $(4.03)$ & $F$ & & $(26134 \cdot 2)$ & \\
\hline${ }_{4} D$ & 8537 & $(3420 r \cdot 9)$ & $(4.01)$ & $F$ & & $(17164 \cdot 6)$ & \\
\hline
\end{tabular}

\begin{tabular}{|c|c|c|c|}
\hline Combination. & $\nu$ & $\lambda$ & Intensity. \\
\cline { 2 - 3 } & & & \\
\cline { 2 - 3 } $3 S-3 p_{2}$ & $32700 \cdot 7$ & $3057 \cdot 15$ & 10 \\
$3 S P P^{2}$ & $59845 \cdot 1$ & $1670 \cdot 98$ & 20 \\
$3 P-3 D$ & $25629 \cdot 3$ & $3900 \cdot 68$ & $10^{1}$ \\
$3 P-4 D$ & $44568 \cdot 3$ & $2243 \cdot 06$ & 4 \\
$3 P-4 S$ & $32776 \cdot 6$ & $3050 \cdot 07$ & 8 \\
$3 D-4 P$ & $17874 \cdot 0$ & $6593 \cdot 23$ & 10 \\
$3 D-4 F$ & $35498 \cdot 7$ & $2816 \cdot \times 8$ & $20^{1}$ \\
$3 D-5 F$ & $44568 \cdot 3$ & $2243 \cdot 05$ & 4 \\
\hline
\end{tabular}

It is probable that, as in $\mathrm{Mg}, \mathrm{Ca}$, etc., ${ }_{3} S$ is the greatest term, and corresponds to the normal state of the atom, and that the inter-system combination ${ }_{3} S-3 p_{2}$ gives a resonance line, strong under moderate excitation. Such a line ought to appear in the arc spectrum of the metal, like the resonance lines of calcium $(\mathrm{H}$ and $\mathrm{K})$. The strong line at $\nu=32700^{\circ} 7$, which Paschen doubts whether to attribute to the neutral or ionised atom, appears to meet these conditions. If it is the resonance line, $3 S=147$ 107.3 and the second ionisation potential is 18.17 volts. The ratio to the corresponding term in $\mathrm{Mg}$ falls in well with those for the $S$-terms. If the ratio $\mathrm{Al}+/ \mathrm{Mg}$ is the same for the $P$ and $p$ terms, $3 P$ for $\mathrm{Al}+$ should be about 85000 , and the principal resonance line ${ }_{3} S-3 P$ near 62000 . There is a very strong line at $59845^{\circ} \mathrm{I}$ which is probably the one-in which case $3 P=87262 \cdot 2$ and the ratio $\mathrm{Al}+/ \mathrm{Mg}=3 \cdot 27$-greater by 0.18 than that found by interpolation between the $p$-terms. The two resonance potentials for $\mathrm{Al}+$, on this interpretation, are $4^{\circ} 04$ and 7.39 volts. In the same fashion $3 D$ may be estimated to be about 63000 , and ${ }_{3} P-3 D$ to be near 24000 . A strong line $25^{62} 9^{\circ} 3$ meets the requirements and leads to the term and ratio given in the Table above. In the same way the line $3 D-4 F$ may be identified (as given at the bottom of the Table). Here we have no corresponding terms in $\mathrm{Mg}$ to guide us, but ${ }_{4} F$ comes out somewhat less than $4 f$, as in $\mathrm{Ca}$ and $\mathrm{Sr}$. The ratio of the ${ }_{4} P$ terms in the two spectra may be anticipated to be about 3.55 (if the $p$-curve runs parallel to the $P$-curve), which leads to the identification of $3 D-4 P$, and an exact value of the latter term. Similarly, the ratio for $4 S$ should be close to $3^{\circ} 00$, and another strong line is found to fit. The identification of $5 F$ is doubtful.

All that can be claimed for this arrangement at present is that it accounts for five of the seven lines of intensity ro or over, which Paschen leaves unidentified, and gives a set of terms the ratios of which to those in $\mathrm{Mg}$ run smoothly and reasonably.

Observations in the extreme ultra-violet should reveal the principal series of singlets and clear the matter up. Experiments with an electric furnace should also settle whether $\lambda_{30} 057$ is the resonance line. This line appears to be present in the solar spectrum. Rowland has an unidentified line of intensity $I$ at $3057^{2} 257$, or $3057^{\prime}$ I 4 I.A., which agrees closely with Paschen's measures. No other lines of $\mathrm{Al}+$ appear, and none should be expected; as on account of the high ionisation and resonance potentials these lines, like 448I Mg, should appear only in hotter stars.

Princeton University Observatory December 3 .

\section{Problems of Hydrone, etc. Luminous Ice.}

IN my recent letter (NATURE, Jan. 26) I refer to Faraday's observation, confirmed by Lenard and Simpson, that a charge can be excited upon drops of water and carried by them only if the water be nearly pure. A similar observation was made by Sir James Dewar, that such water became luminous when cooled in liquid air and then exposed to the beam from a naked arc light. In preparing my Memorial Lecture on Sir James, at the Royal Institution, I took opportunity to confirm his observation and gave the demonstration in my lecture on Friday evening, Jan. I8. Two glass tubes were charged, one with good laboratory-distilled - water (not even conductivity water), the other with tap-water, then sealed off. Both were simultaneously cooled in liquid air, then exposed to the beam: when brought out into the dark room, only the tube containing the distilled water was luminous.

The correlation of Faraday's and Dewar's observations is, I think, of such importance that it is desirable to bring the matter under notice. I hope to be able to determine the critical limit of real acidity at least of the luminous phenomenon. Pure water, were it possible, could not be made luminous, I imagine.

In the lecture, I also showed the glow of ozone. Recent observations by Dr. Downey confirm my belief that the glow of phosphorus is that of ozone.

$$
\text { Henry E. Armstrong. }
$$

P.S.-I am stirred by the photograph in Prof. Duffield's letter printed after mine. Is it not a demonstration of the formation of water from molecules of hydrone under the influence of particles of solid electrolyte-maybe of potassium or ammonium salt-carried up in the smoke?

\section{Snow and the Survival of Cod Fry.}

IT has been a favourite idea with marine biologists in recent years that a connexion exists between the amount and timely efflorescence of plankton algæ and the success of propagation of certain sea fishes, the fry of which are directly or indirectly dependent upon the plankton algæ for their food. The correctness of this view has been demonstrated at least as regards the mackerel on the south coast of England by Prof. E. J. Allen, who traces the ultimate cause of the algal growth back to more or less abundant

$$
\text { No. } 283 \text { I, vol. I I } 3 \text { ] }
$$

